\title{
EDUCAÇÃO INFANTIL E AFETO: TECENDO OS FIOS, DESATANDO NÓS, CONSTRUINDO IDEIAS, DESEMPAREDANDO A VIDA E AS INFÂNCIAS
}

\author{
EARLY CHILDHOOD EDUCATION AND AFFECTION: WEAVING THE THEADS, UNTAKING \\ KNOTS, BUILDING IDEAS, UNPACKING LIFE AND CHILDREN
}

\author{
https://orcid.org/0000-0002-1694-4415 Joice Carvalho Coutinho ${ }^{A}$ \\ https://orcid.org/0000-0002-2765-857X Priscila de Melo Basilio ${ }^{\text {B }}$ \\ (D) ID https://orcid.org/0000-0002-4018-9755 Maria Marta de Andrade Cerqueira ${ }^{\mathrm{C}}$ \\ (iD) https://orcid.org/0000-0003-1097-9542 Diná Teresa Ramos de Oliveira ${ }^{\text {D }}$ \\ ${ }^{\text {A }}$ Universidade Federal do Estado do Rio de Janeiro (Unirio), Rio de Janeiro, RJ, Brasil \\ ${ }^{\text {B }}$ Universidade Federal do Rio de Janeiro (UFRJ), Rio de Janeiro, RJ, Brasil \\ ${ }^{\mathrm{C}}$ Grupo Infâncias Tradições Ancestrais e Cultura Ambiental (Unirio), Rio de Janeiro, RJ, Brasil \\ ${ }^{D}$ Grupo Infâncias Tradições Ancestrais e Cultura Ambiental (Unirio), São Paulo, SP, Brasil \\ Recebido em: 13 dez. 2021 | Aceito em: 2 fev. 2022 \\ Correspondência: Joice Carvalho Coutinho (joiceccoutinho@yahoo.com.br)
}

\begin{abstract}
Resumo
Este artigo é resultado dos estudos desenvolvidos no contexto do Grupo de Pesquisa "Infâncias Tradições Ancestrais e Cultura Ambiental" (Gitaka). Interessadas no debate em torno da educação infantil e dos afetos, este estudo tece primeiramente um diálogo entre filosofia subversiva de Baruch Spinoza e autoras/es que apontam para uma perspectiva pedagógica decolonial, antirracista, anticapitalista, brincante, indígena, quilombola e, por que não, antropofágica. Essas pedagogias ao longo do texto trazem em seu bojo a alegria e o desemparedamento das infâncias (Tiriba, 2018). A partir destas reflexões, apresentaremos também experiências quintaleiras de crianças e educadoras compartilhadas nos encontros "ConversatóriosFinaflor".
\end{abstract}

Palavras-chave: Infâncias; Educação Infantil contra hegemônica; Desemparedamento; Quintais.

\begin{abstract}
This article is the result of studies developed in the context of the Research Group "Children, Ancestral Traditions and Environmental Culture" (Gitaka). Interested in the debate around early childhood education and affections, this study first weaves a dialogue between the subversive philosophy of Baruch Spinoza and authors who point to a pedagogical perspective that is decolonial, anti-racist, anti-capitalist, joker, indigenous, quilombola and, why not, anthropophagic. These pedagogies, throughout the text, bring with them the joy and disembarrassment of childhood (Tiriba, 2018). Based on these reflections, we will also present the backyard experiences of children and educators shared in the "Conversatórios Finaflor" meetings.
\end{abstract}

Keywords: Childhoods; Early childhood education counter-hegemonic; Disengagement; Backyards. 


\section{Educação Infantil e afeto: tecendo os primeiros fios}

Eu não amava que botassem data na minha existência. A gente usava mais era encher o tempo. Nossa data maior era o quando. O quando mandava em nós. A gente era o que quisesse ser só usando esse advérbio. Assim, por exemplo: tem hora que eu sou quando uma árvore e podia apreciar melhor os passarinhos. Ou tem hora que eu sou quando uma pedra. E sendo uma pedra eu posso conviver com os lagartos e os musgos. Assim: tem hora eu sou quando um rio. E as garças me beijam e me abençoam. Essa era uma teoria que a gente inventava nas tardes. Hoje eu estou quando infante. Eu resolvi voltar quando infante por um gosto de voltar. Como quem aprecia de ir às origens de uma coisa ou de um ser. Então agora eu estou quando infante. Agora nossos irmãos, nosso pai, nossa mãe e todos moramos no rancho de palha perto de uma

aguada. $O$ rancho não tinha frente nem fundo. $O$ mato chegava perto, quase roçava nas palhas. A mãe cozinhava, lavava e costurava para nós.

Manoel de Barros, 2006, p.8

Este artigo é resultado dos estudos desenvolvidos no contexto do Grupo de Pesquisa Gitaka. Interessadas no debate em torno da educação infantil e dos afetos, este estudo tece, primeiramente, um diálogo entre a filosofia subversiva de Baruch Spinoza e autores/as que apontam para uma perspectiva pedagógica decolonial, antirracista, anticapitalista, brincante, indígena, quilombola e, por que não, antropofágica - Pedagogias estas que vamos discorrer ao longo do texto, trazendo em seu bojo a alegria e o desemparedamento das infâncias. A partir destas reflexões, apresentaremos, em uma segunda parte do texto, o encontro da criança com a natureza e da natureza com as infâncias que se dá nos quintais brasileiros, numa perspectiva de educação infantil quintaleira como forma de resistência e de potência de vida, de encantamento, de conexão, de pluralidade, de presença, de plenitude e de vivacidade.

Como pesquisadoras, buscamos conceitos e práticas que nos permitissem compreender, abrir caminhos e reinventar um modo de a criança viver suas experiências em diferentes ambientes, sejam escolares, em praças, parques ou quintais. Que elas possam ter espaços para relações com a natureza e que não distancie o humano de suas dimensões essenciais, não qualifique os caminhos da imaginação e da criação e não contribua para a formação de corpos dóceis e submissos. 
Pedimos licença a Manoel de Barros para usarmos a data maior "o quando" - quando infantes vivemos, sorrimos, brincamos, estudamos em muitos espaços, cada uma de nós em suas lutas e alegrias vividas em diferentes contextos, mas em comum (hoje) temos "o quando infante" no grupo de pesquisa Gitaka.

O grupo de pesquisa, desde as suas origens, desenvolve estudos, ações de extensão e de ensino comprometida com a qualificação do cotidiano em relação às necessidades de cuidar de mim (ecologia pessoal); cuidar de nós, do coletivo (ecologia social); e cuidar da natureza (ecologia ambiental) (GUATTARI, 1990). Através de metodologias coerentes com essa perspectiva, aposta na criação de metodologias de educação de crianças de 0 a 6 anos e de formação de professoras/es que se situam nas interfaces entre os campos da Educação Infantil, da Educação Popular, da Educação Ambiental e da Educação Escolar Indígenai ${ }^{i}$ O grupo vem se dedicando a criar, experimentar e sistematizar metodologiasdecoloniais-teórico-brincantescantantes-dançantes-naturantes em cursos de graduação e especialização de professores/as de Educação Infantil, em função da amplitude da temática investigada.

O grupo tem como suas bases teóricas a filosofia europeia não hegemônica de Baruch Spinoza $^{\mathrm{ii}}$ (1632-1677) e caminha com as contribuições das cosmovisões e filosofias dos povos indígenas brasileiros, especialmente de Ailton Krenak e Daniel Munduruku, que também dialogam com os estudos da Antropologia da Criança - Antonela Tassinari, Clarice Cohn e Sandra Benites, e estudos de Leonardo Boff, Humberto Maturana, Célestin Freinet, Félix Guattari, Nêgo Bispo, Luiz Rufino, dentre outros.

A pesquisa tem alguns princípios de que os humanos são seres da cultura e da natureza (ancoradas na filosofia da imanência de Spinoza); os humanos são seres biofílicos, isto é, se constituem em conexão com outros seres e entes não humanos (bióticos e abióticos); a diversidade de espécies potencializa a vida; os humanos são extensão da substância maior que é a natureza; os humanos são modos de expressão que vivem em conexão com outros modos; os seres vivos perseveram/insistem em se manter íntegros (conatus); o ser humano é vontade de potência; o direito ao ambiente como direito à vida. ${ }^{\text {iii }}$

No ano de 2021, uma de nossas ações junto ao grupo foi a realização dos "ConversatóriosFinaflor" - encontros de reflexão e debate em torno das infâncias do campo e da cidade, de territórios indígenas e tradicionais. Os "ConversatóriosFinaflor" ocorreram em quatro encontros, toda última quinta-feira de cada mês, de agosto a novembro. Participaram educadoras/es comprometidos com pedagogias que acolhessem todas as formas de vida, humanas e não-humanas, que fizessem a crítica ao individualismo e ao antropocentrismo, que 
propagassem a amizade, a solidariedade, valorizassem a autonomia, afirmando a soberania dos povos e se colocando contra as injustiças socioambientais que assolam nosso país. Ao longo dos quatro encontros, que estão disponíveis no canal do YouTube Nina Unirio, estiveram conosco Luiz Rufino, Walter Kohan, Paula Henning, Diná Ramos, Laura Santos, Stela Caputo, Nêgo Bispo, Marcia Ramos, Jader Janer Lopes e Frederico Loureiro, além de vídeos-relatos de parceiras ZarkuI zquierdo, Juliana Tupinambá, Luciana Ribeirinha do Pará, Rita Jaqueline Moraes, Bruna Moraes, Maria Marta Cerqueira e Carolina Tupinambá e Movimento Quintais Brincantes. No texto traremos algumas experiências apresentadas no "ConversatóriosFinaflor" que nos ajudaram a contextualizar a educação infantil e os afetos.

Considerando que desde a mais tenra infância as crianças são inseridas na lógica dominante, se não forem repensadas em sua estrutura espacial, metodológica e curricular, as escolas permanecerão como ambientes onde esta lógica de produção neoliberal se naturaliza e é reproduzida. Na contramão desta perspectiva, é fundamental oferecer, em diferentes espaços e na formação dos profissionais da educação, condições para que os relacionamentos aconteçam, as expressões corporais sejam permitidas e a imaginação e a ação sejam instigadas.

A forma de vida que o sistema capitalista impõe aos povos do planeta fragiliza as relações sociais e rompe a compreensão de que somos seres da natureza, de que também a constituímos. Reforçado pelo processo de globalização da economia, este sistema tem como objetivo o controle dos corpos, seus desejos e a captura da alegria. Neste sentido, a partir do conceito de Conatus de Spinoza (SPINOZA, 2020), podemos afirmar que a potência de existir e de agir é constantemente diminuída, que os afetos e as afecções, que mais marcam esse modelo de sociedade, são de tristeza ou de falsas alegrias.

O esforço em perseverar no ser é o que Spinoza chama de Conatus. O filósofo afirma em sua Proposição 6 "cada coisa esforça-se, tanto quanto está em si, por perseverar em seu ser" e como demonstra "nenhuma coisa tem em si algo por meio do qual possa ser destruída, ou seja, que retire a sua existência" (SPINOZA, 2020, p.105).

Viver é sentir com o corpo inteiro, sentir pelo afeto, como diz Spinoza "o corpo humano pode ser afetado de muitas maneiras, pelas quais sua potência de agir é aumentada ou diminuída" (SPINOZA, 2020, p.99). Por isso, defendemos infâncias brincantes que tenham acesso ao ambiente natural e que possam se relacionar com o outro, consigo mesmas, entendendo que esses são bons encontros.

Esse modelo social pautado hegemonicamente na racionalidade também é aquele que fortalece a dicotomia corpo e mente, cultura e natureza, razão e emoção, erudito e popular, 
homem e natureza, de hierarquizações do saber e do viver, dentre outras questões. Neste sentido, a nossa sociedade, com seus aparatos de pensamento e de modos de vida que enfraquecem a potência de existir e resistir, também contribui e fomenta para um distanciamento cotidiano das pessoas e da vida em conexão com a natureza, bem como sabemos, promove uma desvalorização dos saberes tradicionais, populares, intuitivos e sensíveis.

Neste contexto histórico e social também se encontra a educação infantil que, diante de um paradigma educacional eurocêntrico, racionalista, tecnocrático, meritocrático, dentre outros, coloca-se também diante da negação dos nossos desejos, das nossas origens, histórias e da natureza. Neste sentido, juntamo-nos às educadoras/es a refletir sobre a urgência de promover um encontro das infâncias com a sua potência, na construção de uma educação infantil com direito à alegria, em busca de pedagogias ecológicas, populares e libertárias, parafraseando o título da obra de Tiriba (2018).

Nossos afetos são direcionados, capturados e controlados por um sistema que oprime, determina e homogeneíza os saberes, numa única perspectiva. Precisamos levar em conta que: a história única cria estereótipos, e o problema com os estereótipos não é que sejam
mentira, mas que são incompletos [...] ela rouba a dignidade das pessoas. Torna difícil
o reconhecimento da nossa humanidade em comum. Enfatiza como somos diferentes
e não como somos parecidos (ADICHIE, 2019, p.26-27)

Existem práticas que se repetem muitas vezes nas escolas, mas também são encontradas em outros espaços, orientadas para civilizar e homogeneizar, que desconsideram as crianças em sua potência, não levam em conta a sua história, seus saberes, desejos e experiências. Tais práticas expulsam as crianças, pois são pensadas de modo a formar corpos obedientes, dóceis e disciplinados. O corpo humano entra numa maquinaria de poder que o esquadrinha, o desarticula e o recompõe. É como colocar uma criança atrás da outra ${ }^{\text {iv }}$, sentar em cadeiras enfileiradas, ficar sentado horas seguidas, sem a possibilidade de dialogar, brincar, interagir com os outros e ter vivências ao ar livre. Até mesmo se pensarmos em algumas práticas nos berçários, onde os bebês que têm poucas possibilidades de se movimentarem, estes vivem um contexto sem direito a tomar sol durante seu período na creche. Desta forma, não há como negar as opressões impostas pelo sistema capitalista atual. Inclusive, a própria arquitetura dos espaços, como praças, ruas, cidades e escolas, precisa considerar as crianças pequenas, por isso é fundamental o trabalho desenvolvido por organizações como a Urban $95^{\nu}$ - iniciativa global que fomenta o protagonismo de bebês, crianças pequenas e cuidadores, no debate sobre os planejamentos urbanos e também nas estratégias de mobilidade, em demais programas e 
serviços oferecidos nas cidades. Para tanto, considera a experiência de crianças com três anos de idade que tem, em média, até $95 \mathrm{~cm}$ de altura.

Portanto, nos contrapomos à ideia de qualquer preparação que ronda bebês e crianças pequenas, seja para se tornar um adulto ou um ser civilizado para ocupar e atender a demanda imposta pela sociedade contemporânea. Apresentaremos, ao longo do texto, a criança e as experiências de educação infantil como vida e potência, que nos convida a habitar esse mundo de um outro modo.

Dessa maneira, acreditamos nas experiências das infâncias como a arte do encontro, da alegria, em comunhão com a natureza, do desemparedamento, do bem viver, do coletivo, da hospitalidade e do acolhimento, contra qualquer tipo de subalternização e desigualdade, portanto, um currículo que segue os passos e caminha junto das crianças, seja nas instituições de educação infantil, nos parques, nas cidades e nas praças.

Pensamos em uma educação em que a criança não seja submetida às vontades e imposições dos adultos e almejamos que elas participem de um currículo que contribua para gerar diálogos, descobertas, interações, brincadeiras - independentes de suas faixas etárias. Nesse contexto, compreendemos a importância de uma educação que escute as crianças, respeite suas singularidades, valorize suas histórias, de suas famílias, da comunidade e do entorno, o que implica na inteireza desse sujeito, no conhecimento da identidade cultural de cada um. Uma educação que forme sujeitos éticos, capazes de ter empatia pelo outro, espírito de coletividade e sensibilidade com os demais seres da biodiversidade.

Como o poeta Manoel de Barros bem nos convida "Como quem aprecia de ir às origens de uma coisa ou de um ser", não queremos eliminar ou embranquecer a diferença dos currículos na teoria de que todos são iguais, e assim, fazer com que as crianças que vivem suas diferentes infâncias necessitem desvincular-se de suas culturas, linguagens e territórios. Pelo contrário, queremos que vivam intensamente suas origens e suas histórias.

\section{[...] o padrão formativo de atos contrários à diversidade, é também contrário à vida e por isso produtor de injustiças cognitivas/sociais. Nesse sentido, o combate e a transgressão às obras e efeitos do colonialismo/colonialidade são demandas de caráter educativo enquanto prática de liberdade (FREIRE, 1996), pois têm como emergência o reposicionamento dos seres diante a tragédia colonial. (RUFINO, 2019, p. 265)}

Assim, apostamos nesses caminhos para uma educação contra-hegemônica e decolonial, uma educação infantil que priorize a conexão com a natureza, rompendo com um discurso desenvolvimentista da modernidade que explora os recursos naturais, provocando uma crise ambiental na ideia de um viver melhor que passa pelo acúmulo de bens, exploração e colonização do outro. 
Ao localizarmos práticas de um currículo brincante em conexão com a vida, queremos abalar, perturbar, deslocar e romper com uma pedagogia tradicional, de modo a criarmos novas formas de abordar as experiências com as crianças, a partir delas e de suas vivências locais, na perspectiva da superação das colonialidades que nos foram impostas.

É urgente superar a concepção de escola que nasceu com a Revolução Industrial e pensar os objetivos da Educação em função de escolhas que envolvam novas formas de pensar a existência humana sobre a Terra; [...] Precisamos de concepções e práticas escolares que assumam os valores da cooperação, amizade, solidariedade e do respeito à diversidade como princípios e como bandeiras. (TIRIBA, 2018, p. 183)

Como modo de resistência, as pesquisadoras Anete Abramowicz e Fabiana Oliveira também apontam sobre o quanto é imprescindível pensar o currículo como criação. Para as autoras, a educação infantil "tem por função alargar o espaço da experiência da infância que é a criação, na medida em que o espaço da criação também necessita ser produzido, em uma espécie de produção da produção do espaço de criar" (ABRAMOWICZ; OLIVEIRA, 2013, p. 294). Muitas vezes, as escolas apagam e silenciam os processos de criação e buscam formas de controle dos desejos das crianças. No entanto, elas ainda encontram brechas, fugas, rastros, caminhos de viverem momentos que fortaleçam a vida e a alegria. A questão é até quando as infâncias resistirão às formas da escola que tem em seu objetivo civilizar e preparar para a ordem já estabelecida.

\title{
Experiências de quintais
}

\begin{abstract}
Acho que o quintal onde a gente brincou é maior do que a cidade. A gente só descobre isso depois de grande. A gente descobre que o tamanho das coisas há que ser medido pela intimidade que temos com as coisas. Há de ser como acontece com o amor. Assim, as pedrinhas do nosso quintal são sempre maiores do que as outras pedras do mundo. Justo pelo motivo da intimidade [...] Se a gente cavar um buraco ao pé da goiabeira do quintal, lá estará um guri ensaiando subir na goiabeira. Se a gente cavar um buraco ao pé do galinheiro, lá estará um guri tentando agarrar no rabo de uma lagartixa [...]
\end{abstract}

(Manoel de Barros)

Experiências de quintais, quem é que não tem uma para contar? A imensidão de um quintal e as crianças desses quintais nos convidam a uma reflexão pulsante em nossos corações e nos estudos que temos realizado no Grupo de pesquisa. Desemparedamento da vida, brincar 
livre, experiências que potencializam a existência e biofilia são alguns princípios que orientam nossas reflexões e ações no mundo.

Seja um grande quintal da casa ou pequeno, seja a rua da casa ou um terreno próximo, uma praça ou o sítio dos tios ou avós, espaços ao ar livre das escolas - maiores com horta, árvores, barro ou gramado, parques, ou menores somente com uma árvore. Sejam quais forem esses quintais das nossas experiências vividas, é bem possível que importantes memórias nos marquem e façam parte de quem somos hoje. Entendemos que são esses quintais e seus seres que convidam as crianças às experiências livres, de terra, lama, sorrisos, gritos, imaginação, criação, correria, calmaria, narrativas, amizades e quantas outras mais forem possíveis. As crianças aceitam o convite, afetam e são afetadas por esses espaços, seres e acontecimentos. Santos (2018) a partir de Spinoza afirma: "Somos seres, modos extensos da substância única (o universo), e vivemos e nos constituímos na relação com todos os outros seres e coisas existentes neste universo." (SANTOS, 2018, p. 190). A autora relata que:

No meu tempo de infância [...] a natureza era primordial; embora meus irmãos e eu não nos déssemos conta do quão primordial era, pois a tínhamos ali diante de nós em abundância. Era na natureza que construíamos nossas casas em cima das árvores, tomávamos banho de cachoeira e nos deliciávamos com os frutos nas diferentes estações. [...] Era nas árvores, na natureza, que a vida acontecia e que nós crianças humanas nos constituíamos das mais diversificadas afecções que esta nos proporcionava. (SANTOS, 2018, p.189)

Terra, mato, vento, água, gravetos, pedras, animais, brincadeiras de esconder, correr, fazer comidinha de lama e folhas, subir nas árvores, descansar observando o sol, o barulho dos pássaros e outros bichos, passar tempo nos braços da árvore, comer frutos, respirar. Alegria, sujeira, amizades, aprendizagens, afetos, tudo se junta e constitui a vida vivida.

Paulo Freire nos conta que seu primeiro mundo foi o quintal de casa. Um lugar especial, repleto de "árvores, cores, cheiros, frutas, que, atraindo passarinhos vários, a eles se davam como espaço para seus cantares." (FREIRE, 1995, p. 24). Segundo o autor, "Antes de tornarme um cidadão do mundo, fui e sou um cidadão do Recife [...] Quanto mais enraizado na minha localidade, tanto mais possibilidades tenho de me espraiar, me mundiatizar [...]"(FREIRE, 1995, p.25). E com boniteza nos diz Freire (1995) ainda que:

O Brasil, na forma como existe para mim, dificilmente existiria sem o meu quintal, a que se juntaram ruas, bairros, cidades. A terra que a gente ama, de que a gente fala e a que se refere, tem sempre um quintal, uma rua, uma esquina, um cheiro de chão, um frio que corta, um calor que sufoca, um valor por que se luta, uma carência, uma língua que se fala em diferentes entonações. (FREIRE, 1995, p.25) 
Entretanto, em que as experiências vivenciadas nos nossos quintais se relacionam com o currículo? Quantas vezes já nos deparamos com situações nas quais as crianças são tratadas como um ser do futuro, um "vir a ser", e não como que é no aqui e no agora?

Nesse sentido, Daniel Munduruku reflete sobre o mundo contemporâneo que insiste em perguntar às crianças: "o que você vai ser quando você crescer?"

Eis uma pergunta que nunca me fizeram, na aldeia, quando criança. Nenhum adulto jamais insinuou que eu precisava ser alguma coisa quando me tornasse homem. Somente quando entrei na escola comecei a ouvir essa pergunta e, com ela, vinha a afirmação de que eu precisava ser alguém quando crescesse. Não me lembro de meu pai ou minha mãe terem me obrigado a ser outra coisa além do que eu já era. E o que eu era? Criança. Era a única coisa que eu tinha que ser.

Portanto, eu não precisava ser mais nada. [...] (MUNDURUKU, 2019, p.57)

A criança é! É em suas possibilidades, linguagens, espaços e tempos, ela é e está sendo. É ser potente que experimenta o mundo, o interpreta e recria o tempo inteiro. A pesquisadora Léa Tiriba (2010) nos questiona: "Encantar-se com a beleza do dia [...], ouvir o canto de um pássaro, observar as nuvens brincando no céu [...] que ensinamentos, que aprendizagens, que estados de espírito essas experiências propiciam?” (TIRIBA, 2010, p. 6).

As relações das crianças nos seus quintais de casa, da escola, nas praças e ruas, assim como o conhecimento de suas histórias, suas ancestralidades, nos dão pistas de práticas escolares que levam em consideração as vivências e experiências delas. Pensar um currículo com as crianças em relações afetivas, verdadeiras, respeitosas, na busca por aguçar nossos olhares e ouvidos ao que elas nos mostram e nos dizem sobre quem são e o mundo que desejam construir, pode ser um caminho possível para bons encontros, descobertas potentes e contra hegemônicas. Léa Tiriba, recorrendo aos estudos de Spinoza e Boff, reflete:

[...] a natureza é a vida que se expressa em todos os seres, coisas e fenômenos. As crianças declaram sua paixão pelos espaços ao ar livre, porque são modos de expressão desta mesma natureza (ESPINOSA, 1983), pois a cooperação, a tendência a se associar, a estabelecer elos são características essenciais dos organismos vivos: todas as formas de vida sobre a Terra evoluíram juntas por bilhões de anos, num movimento de coevolução que é a dança da vida em andamento (BOFF,1999). Valorizando esse diálogo da criação, é preciso reinventar os tempos, os espaços, as rotinas das instituições de Educação Infantil, possibilitando que as crianças tenham acesso à vida que está no entorno, isto é, possam manter e alimentar os elos que as afirmam como seres orgânicos. (TIRIBA, 2010, p. 6).

Em reflexão com Tiriba (2010) e Spinoza, entendendo o que Paulo Freire nos diz que "a leitura do mundo precede a leitura da palavra" (FREIRE,1983, p. 11), é importante conhecermos que mundo é esse que a criança lê, quais leituras faz dele, o que há nesse mundo que é bom, o que potencializa a existência e o que há que precisa ser problematizado e reinventado. Precisamos ler o mundo com as crianças, brincar, dialogar, para a construção de 
um currículo vivo, potente e bom para todos/as da escola, das ruas, das praças, da vida. "O fato de me perceber no mundo, com o mundo e com os outros me põe numa posição em face do mundo que não é a de quem nada tem a ver com ele." (FREIRE, 1996, p.53). Nossa presença no mundo é a de quem se insere, cria e transforma, que nada tem a ver com a de um objeto, é de sujeito da história, como aprendemos com Freire. Sendo assim, sonhamos em transformar nosso mundo, seja nosso mundo imediato, como nossa casa, nosso quintal, a nossa escola, seja o bairro, a cidade, o Brasil. Sonhamos e partimos para a luta e a ação. Tiriba (2018) sonha conosco:

Sonhamos com uma escola que seja espaço de acolhida e pertencimento, de liberdade, experimentação e criatividade. As crianças- muitas delas desde os 3 ou 6 meses de idade- permanecem nas IEIs por longos períodos de sua vida, justo os primeiros de sua existência. Nesses lugares, convivem com mães e educadoras, pais, famílias, irmãos, vizinhos [...]com inspiração em Espinosa, podemos dizer que, nas instituições, são produzidos dois modos de existência: um que potencializa a existência; outro que faz sofrer, que enfraquece [...] (TIRIBA, 2018, p. 195)

É acreditando na potência da criança, como ser da natureza, na necessidade de aprendermos com elas, que poderemos pensar um currículo juntas. No decorrer do texto, apontaremos alguns registros de experiências em escolas brasileiras, colhidas do encontro online "ConversatóriosFinaflor infâncias com natureza: desemparedar, florestar...experimentar-se

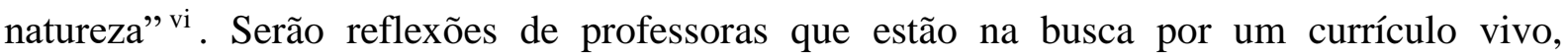
desemparedado, repleto de vivências com as crianças.

A professora de Educação Infantil do Município do Rio de Janeiro, Bruna Moraes ${ }^{\text {vii, }}$ conta que muitas das vivências acontecem no quintal, e estar diariamente com as crianças nesse espaço, faça chuva ou faça sol, é inegociável. Bruna Moraes reflete que o quintal é um lugar de bons encontros e que sempre procura oportunizar às crianças vivências que as potencializam (ConversatóriosFinaflor infâncias com natureza, 2021).

No vídeo, com as experiências das crianças e a professora, passeamos por todo o quintal da escola e brincamos juntos, rolamos na grama com a brincadeira "roda-roda", nos divertimos de nos esconder, observamos o céu, a borboleta, brincamos com as sombras, corremos, vimos um gongolo branco, sentimos e exploramos a terra, plantamos, colhemos e fazemos bolo de cenoura, ouvimos o cantar dos pássaros e pudemos até mesmo sentir o cheiro do "alegrim"viii. Sentimos a alegria e o espaço de afeto que ali se cria todos os dias.

Outro vídeo apresentado "O quintal de nossa infância" ix faz nossos corações transbordarem de esperança. A experiência vem narrada pelas vozes das crianças com fotografias de todo o percurso: 
Nossa escola tinha o desejo de brincar na praça. Havia muito lixo. Fizemos uma campanha. Trocamos o lixo por tábuas. Virou uma lixeira. Todo mundo ajudou. $\mathrm{O}$ papai e os titios limparam tudo. Plantamos muitas flores. Começamos a brincar. Queria chegar mais rápido. Então, um portão ajudaria? Mas lá no fundo, tinha um perigo para os pequenininhos. Tudo resolvido, uma cerca para proteger...Participamos de um projeto! E ganhamos um brinquedo para a praça. Estamos plantando sonhos. Gostamos de ler em qualquer lugar. Nossa história não para por aqui. Gostamos de brincar na praça. (ConversatóriosFinaflor infâncias com natureza, 2021)

As vivências afetivas entre as crianças e seus pares e as crianças-natureza, continuam na Escola Municipal de Educação do Campo Maria Clemildes ${ }^{\mathrm{x}}$. A professora Luciana Oliveira investigou, na sua pesquisa de mestrado, as crianças ribeirinhas da Amazônia, atuou em sua investigação juntamente com a professora Eliana Maia, na Comunidade do Caruaru, na única escola ribeirinha da região. O vídeo mostrou a infância das crianças ribeirinhas e o saber delas com as águas e a terra. A professora Eliana Maia nos traz uma profunda e necessária reflexão: “A sabedoria da terra, da água, da mata, que elas possam nos inspirar [...] que nós possamos ter a capacidade de reinventar a infância e o brincar [...]" (ConversatóriosFinaflor infâncias com natureza, 2021).

As contribuições de Diná Teresa Ramos de Oliveira ${ }^{x i}$ no mesmo encontro on-line também chamaram muito a atenção para a temática da renaturalização dos espaços de brincar. A pesquisadora de playgrounds naturais e artesanais afirmou se tratar de uma escolha política e pedagógica das escolas a construção de um projeto que vise promover a infância e a natureza em comunhão, uma reconexão do humano com a natureza viva e potente. Assim, afirmou que se tratam de escolhas políticas pedagógicas ter horta, galhos e gravetos, pedras soltas, composteiras, minhocas, gongolos, terra, água, lama, montanhas de folhas e tocos. Brincar na chuva, brincar com água, é claro, ter quintais com árvores, frutas, flores, plantas e todas as vidas que coabitam a terra. Ter mata e mato, bosques, jardins e ter uma floresta no nosso horizonte pedagógico. É também uma escolha ter brinquedos de madeira, de galhos, de tocos e troncos, de bambu e de sementes. Afirmando que sim, podemos e devemos ter balanços, escorregadores e outros desses brinquedos que já datam mais de cem anos no Brasil, até podemos ter alguns brinquedos de plástico, porém é importante fazer escolhas simples e ricas, complexas e potentes que vão promover vínculos, sentidos, saberes, sensações, relações e muito mais.

Sabemos que nos diferentes espaços do nosso Brasil há professores/as reinventando o quintal de suas escolas e esse é nosso convite. Sigamos na busca por experiências afetivas, dialógicas, decoloniais, que potencializem a existência, que desemparedem a vida, acolham a diversidade, reinventem o mundo e alegrem nossos corações. 


\section{Nosso quintal é maior que o mundo, ele não termina aqui...}

Moramos no quintal e o quintal mora dentro de nós... Cada um é um quintal e nesses quintais vivenciamos o inesperado, o inacabado, as possibilidades, belezas, encontros, alegrias, descobertas, sentimos com o corpo inteiro. O quintal é onde pode acontecer tudo, mas é preciso oportunizar para que assim experimentemos o desemparedamento.

Sabemos que milhares de escolas no Brasil não possuem áreas externas, e sua arquitetura é pensada de forma a docilizar os corpos, que o desafiador período de pandemia retoma a importância das construções das instituições da educação infantil, de terem um olhar para as crianças e seus corpos livres, seus deslocamentos e conexões com a natureza. Por isso a importância de nos comprometermos na tentativa de garantir isso nas discussões dos planos municipais, das propostas curriculares e de todos os documentos produzidos para essa faixa etária, propondo um olhar para o desemparedamento seja na arquitetura, seja nas relações.

Somos extensão da natureza, como aprendemos com Spinoza, portanto, ao estarmos ao ar livre, estamos em conexão com o que somos, e isso potencializa a nossa existência. Por isso, acreditamos nos bons encontros, defendemos a criança como ser da natureza. As experiências são sempre singulares, não objetivamos trazê-las como colonizadores, mas intencionamos provocar deslocamentos, convites às reflexões, reinvenções, experimentações e sensações para práticas curriculares pedagógicas libertárias, populares e ecológicas.

Sim! É possível acreditar e viver em comunhão consigo mesmo, com o outro e com o todo! Sim, é possível rolar na grama, contemplar o céu, subir em árvores, comer frutas do pé e lambuzar-se, enlamear-se e sentir a força e a grandeza do universo. É muito encantador embrenhar-se de infâncias, desemparedar a si e a vida, encantar-se, florestar-se, renaturalizarse, experimentar-se natureza. Viver a boniteza da vida e os afetos de alegria!

Para isso precisamos ter sempre em vista em quais contextos educacionais, escolares ou não, estamos inseridas, a partir dessas realidades desenvolver e adotar estratégias para resistir e promover nas cidades e nos interiores uma educação de infâncias com vidas pulsantes, de alegria, liberdade, amor e acolhimento, de encantamento, plenitude e vivacidade, de resistência e muitas potências, uma escola que deseja ser e estar em comunhão com as infâncias e com a Mãe Terra.

E o seu quintal, como é? Acolhe as diferenças, é alteritário e se abre ao imprevisível? Possibilita a conexão com a natureza, o diálogo e a escuta sensível, o respeito às singularidades e às histórias de cada um? (FREIRE, 1996). 
Nesse quintal cabem nossas inquietações, dúvidas, questionamentos, mas também cabem parcerias, trocas, descobertas, alegrias, encontros, desejos; afinal esse quintal é maior que o mundo!

\section{Referências}

ABRAMOWICZ, Anete; OLIVEIRA, Fabiana de. A infância analisa a educação básica. Revista Education Acta Scientiarum, Maringá, v.35, n.2, p. 293-300, jul./dez. 2013. Disponível em:https://periodicos.uem.br/ojs/index.php/ActaSciEduc/article/view/20639. Acesso em: 30 nov. 2021.

ADICHIE, Chimamanda Ngozi. O perigo de uma história única. São Paulo: Companhia das Letras, 2019.

BARROS, Manoel de. Memórias inventadas: as infâncias de Manoel de Barros. São Paulo: Editora Planeta do Brasil, 2008.

BARROS, Manoel de. Memórias inventadas: a segunda infância. São Paulo: Editora Planeta do Brasil, 2006.

ConversatórioFinaflor infâncias com natureza: desemparedar, florestar...experimentar-se natureza. Realizado em: 30/09/2021. Disponível em: https://www.youtube.com/watch?v=yZjYQpiM2Vg. Acesso em: 30 nov. 2021.

FREIRE, Paulo. A importância do ato de ler: em três artigos que se completam. São Paulo: Autores Associados; Cortez, 1983.

FREIRE, Paulo. À sombra desta mangueira. São Paulo: Editora Olho d’água, 1995.

FREIRE, Paulo. Pedagogia da autonomia: saberes necessários à prática educativa. São Paulo: Paz e Terra, 1996.

GUATTARI, Felix. As três ecologias. Campinas: Papirus, 1990.

MUNDURUKU, Daniel. Das coisas que aprendi: ensaios sobre o bem-viver. Lorena: DM Projetos Especiais, 2019.

RUFINO, Luiz. Pedagogias das encruzilhadas. Rio de Janeiro: Mórula Editorial, 2019.

SANTOS, Zemilda do Carmo Weber do Nascimento. Criança e a experiência afetiva com a natureza. Curitiba: Appris, 2018.

SPINOZA, Baruch. Ética. Belo Horizonte: Autêntica, 2020.

TIRIBA, Léa. Criança da natureza. Anais do I Seminário Nacional Currículo em Movimento Perspectivas Atuais. Belo Horizonte, novembro de 2010. 
TIRIBA, Léa. Educação Infantil como direito e alegria: em busca de pedagogias ecológicas, populares e libertárias. Rio de Janeiro/São Paulo: Paz e terra, 2018.

iParágrafo retirado do Relatório do Grupo de Pesquisa Gitaka, 2020.

ii O Grupo Gitaka, no ano de 2021, criou três frentes de estudos, uma delas com a temática das Filosofias Europeias não Hegemônicas. Realizamos os estudos com a orientação da Professora Dra. Zemilda do Carmo Weber do Nascimento dos Santos.

iiiParágrafo retirado do documento "Apontamentos sobre uma metodologia Teórico Brincante para o Currículo da Escola de Educação da Unirio", localizado no acervo do Grupo Gitaka.

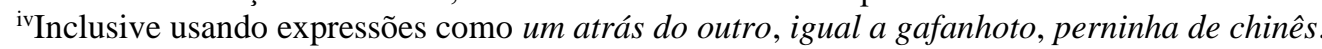

vhttps://urban95.org.br/.

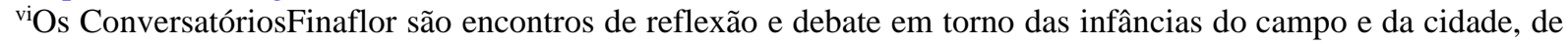
territórios indígenas e tradicionais, disponíveis no canal do Youtube Nina Unirio.

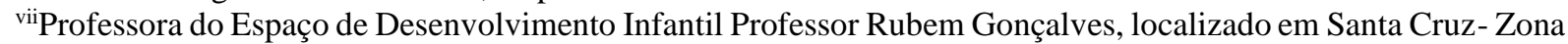
Oeste do Rio de Janeiro.

viii“Alegrim": como uma criança se refere ao "alecrim”, no vídeo apresentado.

${ }^{i x}$ Experiência da EMEI Professor Ernest Sarlet (Secretaria Municipal de Novo Hamburgo), apresentada pela Professora Viviane Scheneider.

${ }^{x}$ Localizada na comunidade do Caruaru- Ilha do Mosquiero, Belém/PA.

${ }^{x i}$ Diná é participante do Coletivo Parque de Bambu, que pesquisa e cria instalações lúdicas com materiais naturais de forma artesanal, a partir de processos de observação das crianças brincando em ambientes naturais. 